\title{
A Rare Case of Non-Gestational Metastatic Ovarian Choriocarcinoma: Case Report and Literature Review With a Special Emphasis on Imaging
}

Abdul Sattar Anjum ${ }^{1}$, Hamza Maqsood ${ }^{2}$, Shifa Younus ${ }^{3}$, Sadia Anjum ${ }^{1}$, Maham Fatima ${ }^{1}$

1. Radiology, Nishtar Medical University, Multan, PAK 2. Cardiology, Nishtar Medical University, Multan, PAK 3. Internal Medicine, Nishtar Medical University, Multan, PAK

Corresponding author: Hamza Maqsood, chmaqsood220@gmail.com

\begin{abstract}
Non-gestational choriocarcinoma of the ovary is a very rare neoplasm. It carries a worse prognosis as compared to gestational choriocarcinoma (GCC). Here, we report a case of non-gestational ovarian choriocarcinoma. The patient initially presented in a medical emergency with abdominal pain, a feeling of heaviness in the lower abdomen, cough, and dyspnea. The patient had four healthy children, and the last childbirth was five years ago. There was no history of any abortion or stillbirth in the past four years. A highly vascular left adnexal mass was observed on ultrasound abdomen and pelvis. Compute CT chest, abdomen, and pelvis were performed, which revealed metastatic left ovarian choriocarcinoma features. It also showed vascular metastases of the carcinoma in the kidneys, liver, and lungs. We report this case specifically emphasizing ultrasound, multidetector computed tomography (MDCT), and CT angiography findings.
\end{abstract}

Review began 01/27/2021 Review ended 02/01/2021 Published 02/04/2021

๑) Copyright 2021

Anjum et al. This is an open access article distributed under the terms of the Creative Commons Attribution License CC-BY 4.0., which permits unrestricted use, distribution, and reproduction in any medium, provided the original author and source are credited.
Categories: Internal Medicine, Obstetrics/Gynecology, Radiology

Keywords: gestational, ovarian choriocarcinoma, mdct, ct angiography

\section{Introduction}

Germ cell malignancies represent $15 \%$ of ovarian cancers in Asian and African-American nations [1]. There are three ways by which ovarian choriocarcinoma can arise. These include primary tumors associated with ovarian pregnancy, a metastatic carcinoma from primary gestational choriocarcinoma in other parts of the genital tract, and a germ cell tumor admixed with other neoplastic germ cell elements [2].

Non-gestational choriocarcinoma is usually a component of mixed germ cell tumors (MGCTs). MGCTs include immature teratoma, endodermal sinus tumor, embryonal carcinoma, and dysgerminoma [3]. Isolated non-gestational choriocarcinoma of the ovary is an extremely rare neoplasm. It has a worse prognosis when compared with gestational choriocarcinoma (GCC) [4].

\section{Case Presentation}

Here, we report a case of a 36-year-old female who presented in a medical emergency with complaints of abdominal pain for six months, a feeling of heaviness in the lower abdomen for three months, cough, and shortness of breath month. The patient was para four, and the last childbirth was five years ago. There was no history of any pregnancy or miscarriage in the past four years. She had a history of 19 pints of blood transfusion in the past six months. On general physical examination, we found marked pallor and emaciation. Her abdominal palpation revealed tenderness in the left hemipelvis. As far as her labs are concerned, a complete blood count (CBC) showed hemoglobin (Hb) of $4 \mathrm{~g} / \mathrm{dl}$. Total leucocyte count (TLC), platelets, prothrombin time (PT), and activated partial thromboplastin time (aPTT) were in the normal range. Serum beta-human chorionic gonadotropin (hCG) turned out to be $6000 \mathrm{IU} / \mathrm{ml}$. Abdomen and pelvis ultrasonography (USG) showed an echogenic mass in the left adnexal region that appeared highly vascular on Doppler ultrasound (Figure 1). The uterus was morphologically normal. 


\section{Cureus}

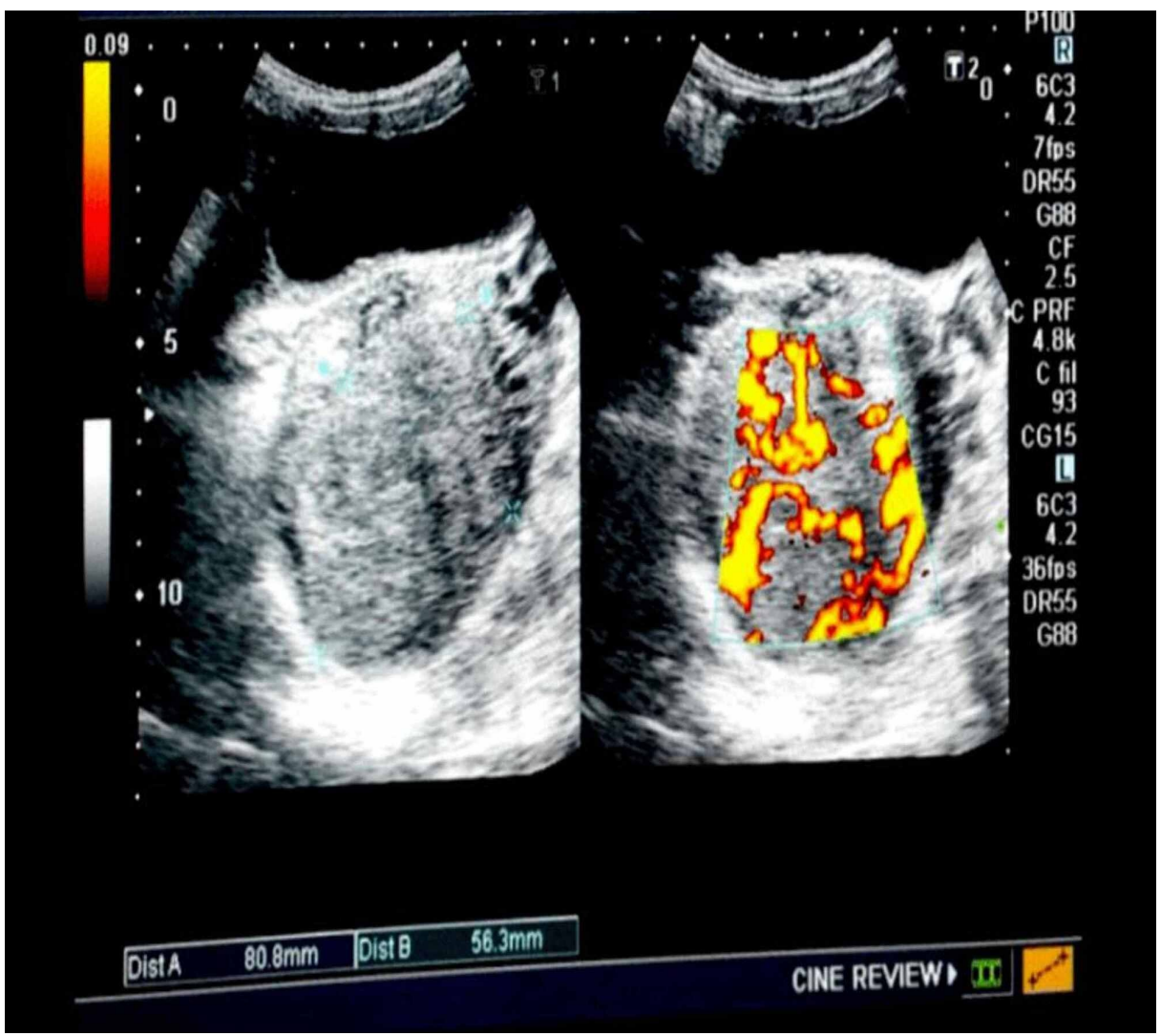

FIGURE 1: Pelvic ultrasound showing an echogenic mass in the left adnexal region. Doppler shows the mass to be highly vascular

We found a highly vascular echogenic mass in the left kidney with a subcapsular collection. USG also revealed a left-sided pleural effusion (Figure 2).

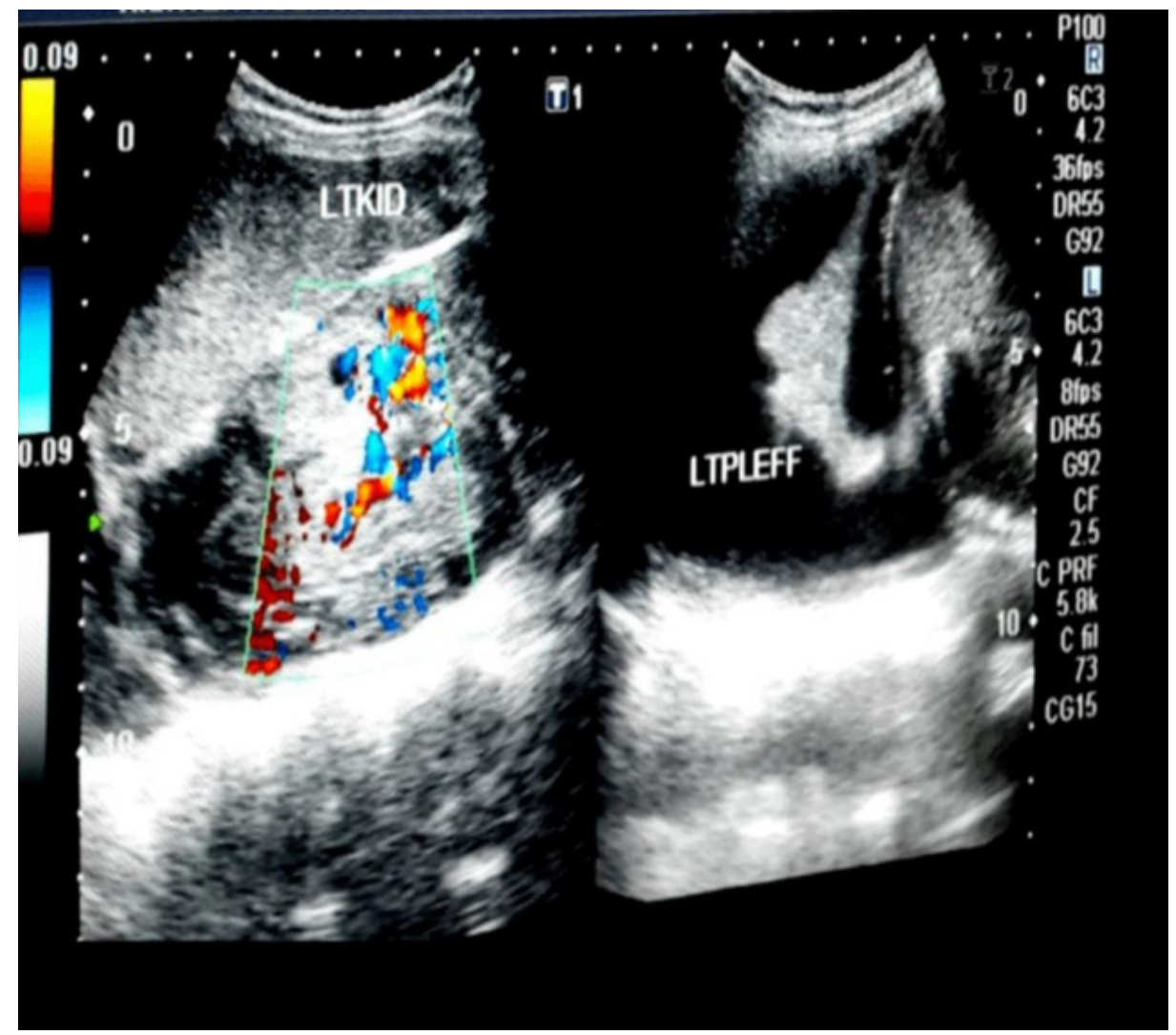




\section{Cureus}

FIGURE 2: Ultrasound abdomen showing a vascular mass in the left kidney and a left pleural effusion

We did CT chest, abdomen, and pelvis, which showed an enhancing left ovarian mass measuring approximately $86 \times 82 \mathrm{~mm}$, associated with vascular lesions in both kidneys and the liver, multiple vascular pulmonary nodules, and bilateral pleural effusion (Figures 3-9).

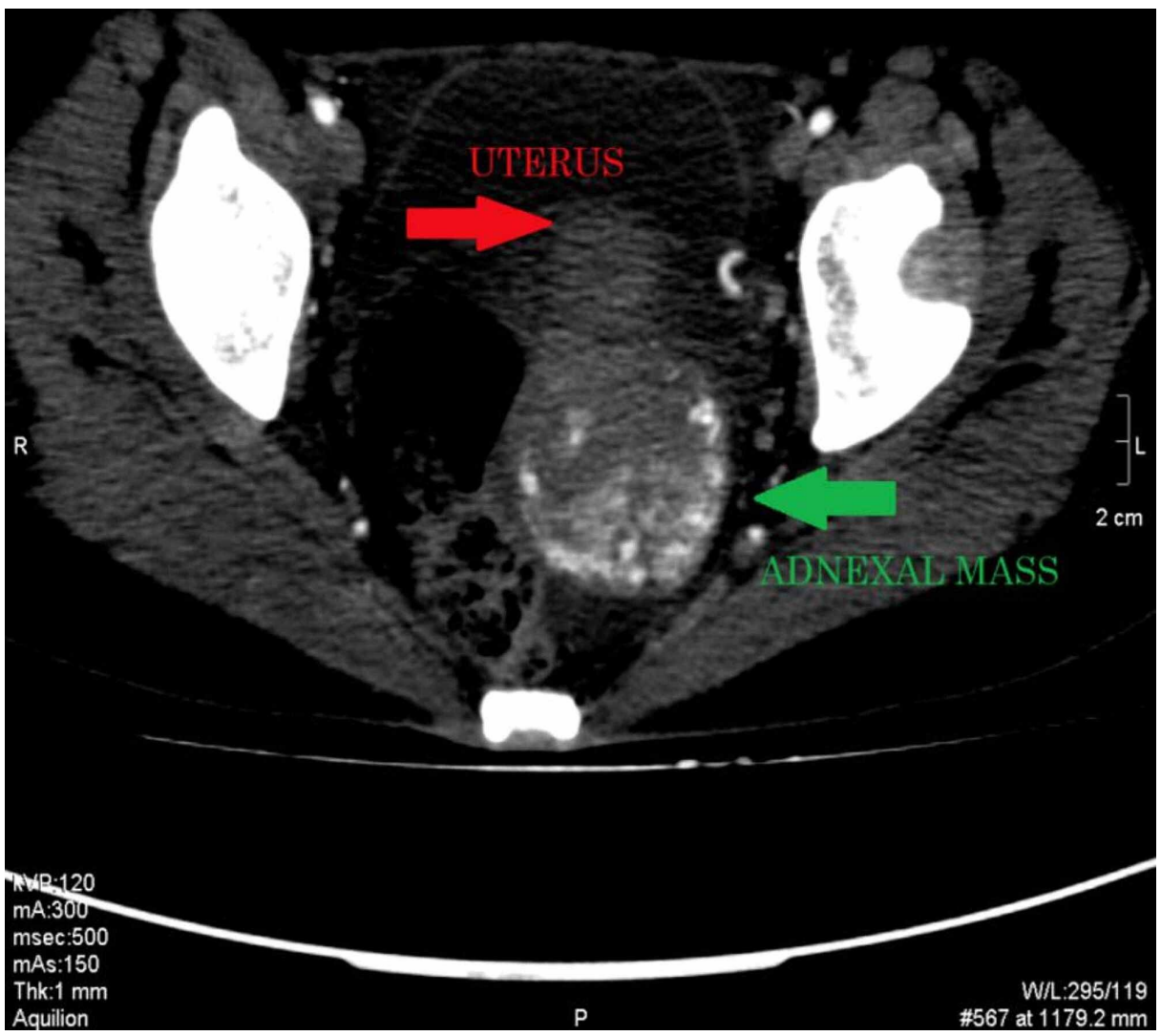

FIGURE 3: CECT pelvis axial section showing a large highly vascular mass in the left adnexal region extending up to the posterior cul-de-sac displacing the uterus anteriorly

CECT: contrast-enhanced computed tomography 


\section{Cureus}

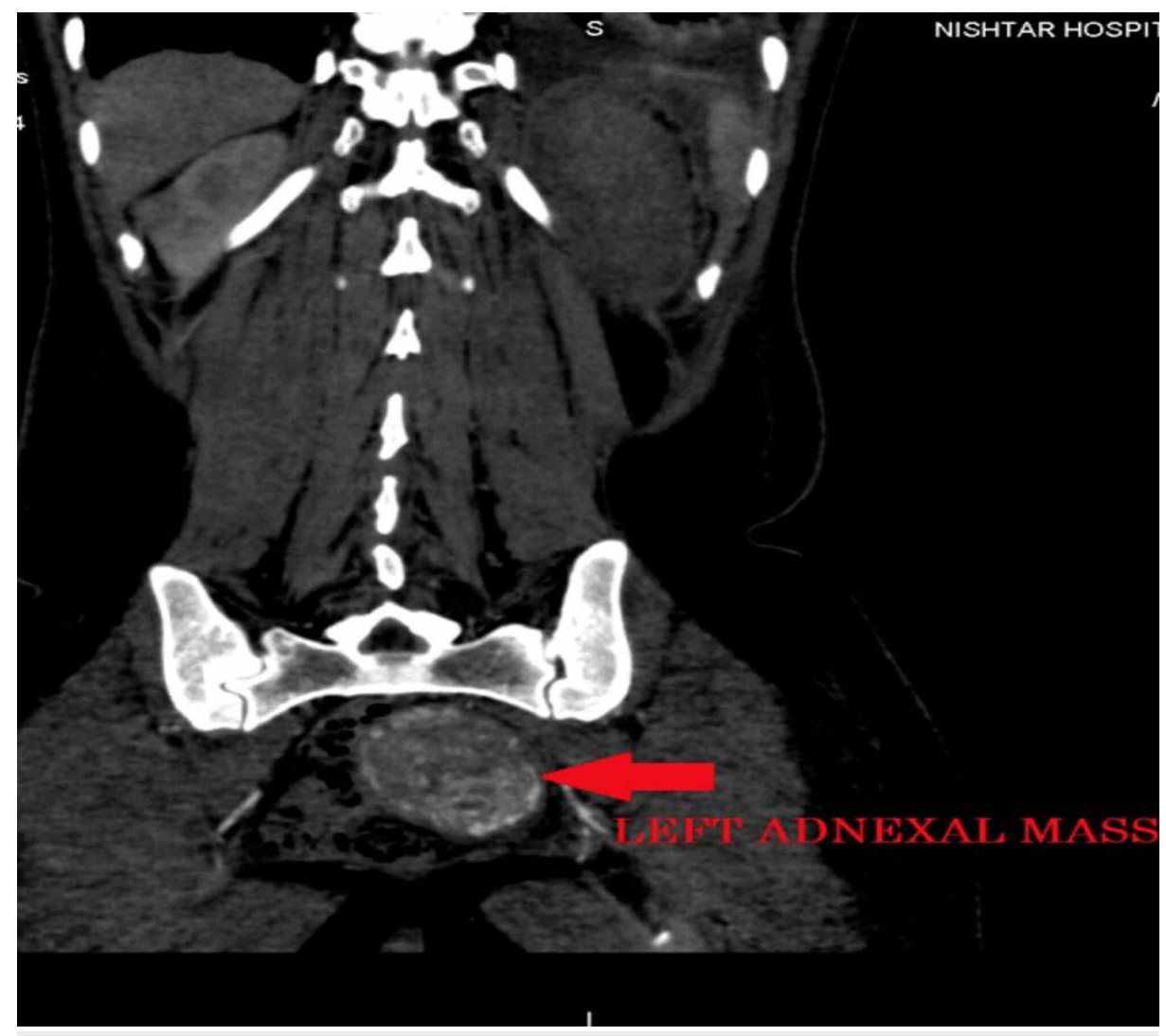

FIGURE 4: Coronal reformat CT showing an enhancing left adnexal mass

CT: computed tomography

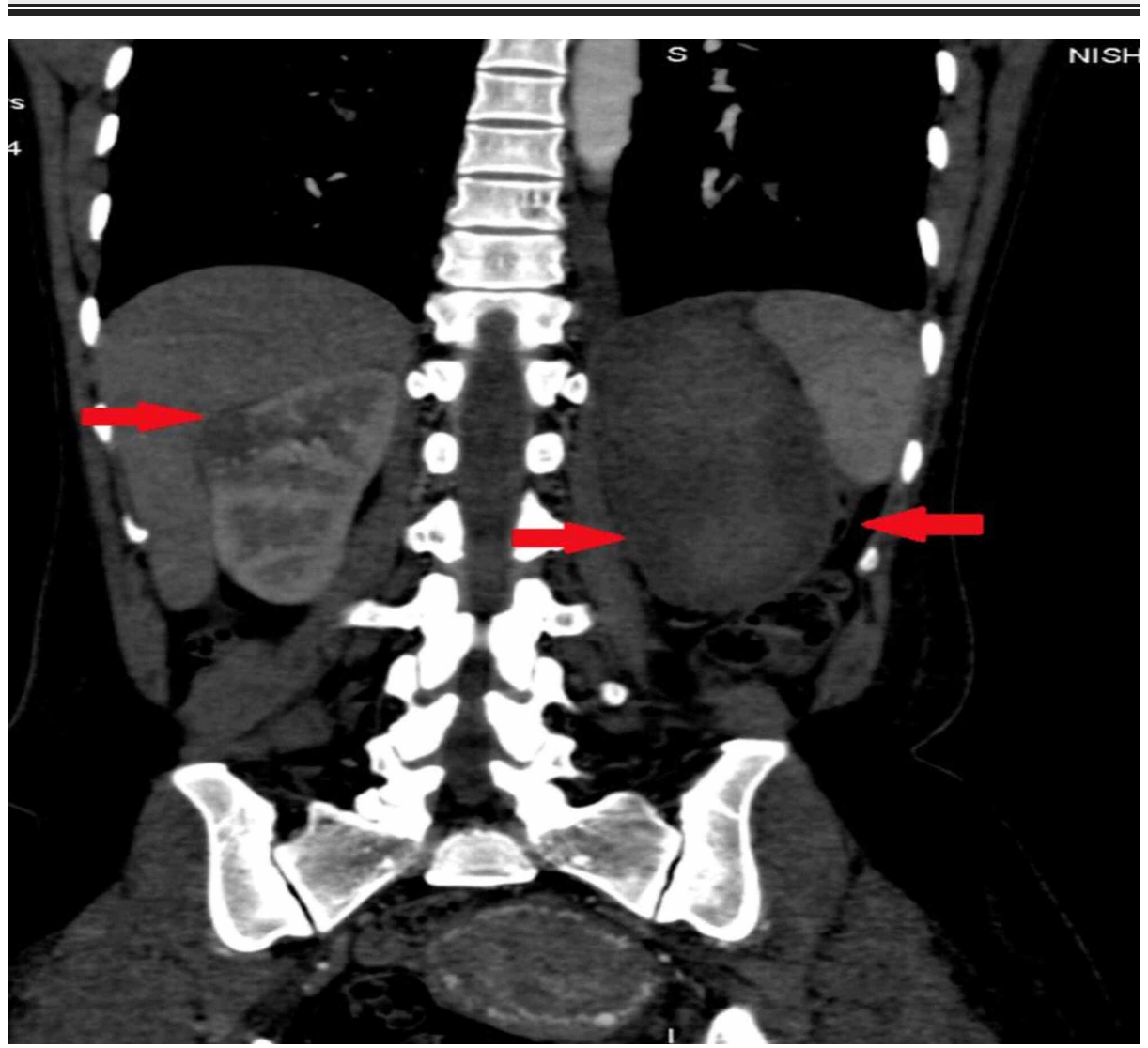




\section{Cureus}

FIGURE 5: CT abdomen coronal reformat showing a soft tissue density mass in the kidney and large subcapsular collection (hematoma) in the left kidney

CT: computed tomography

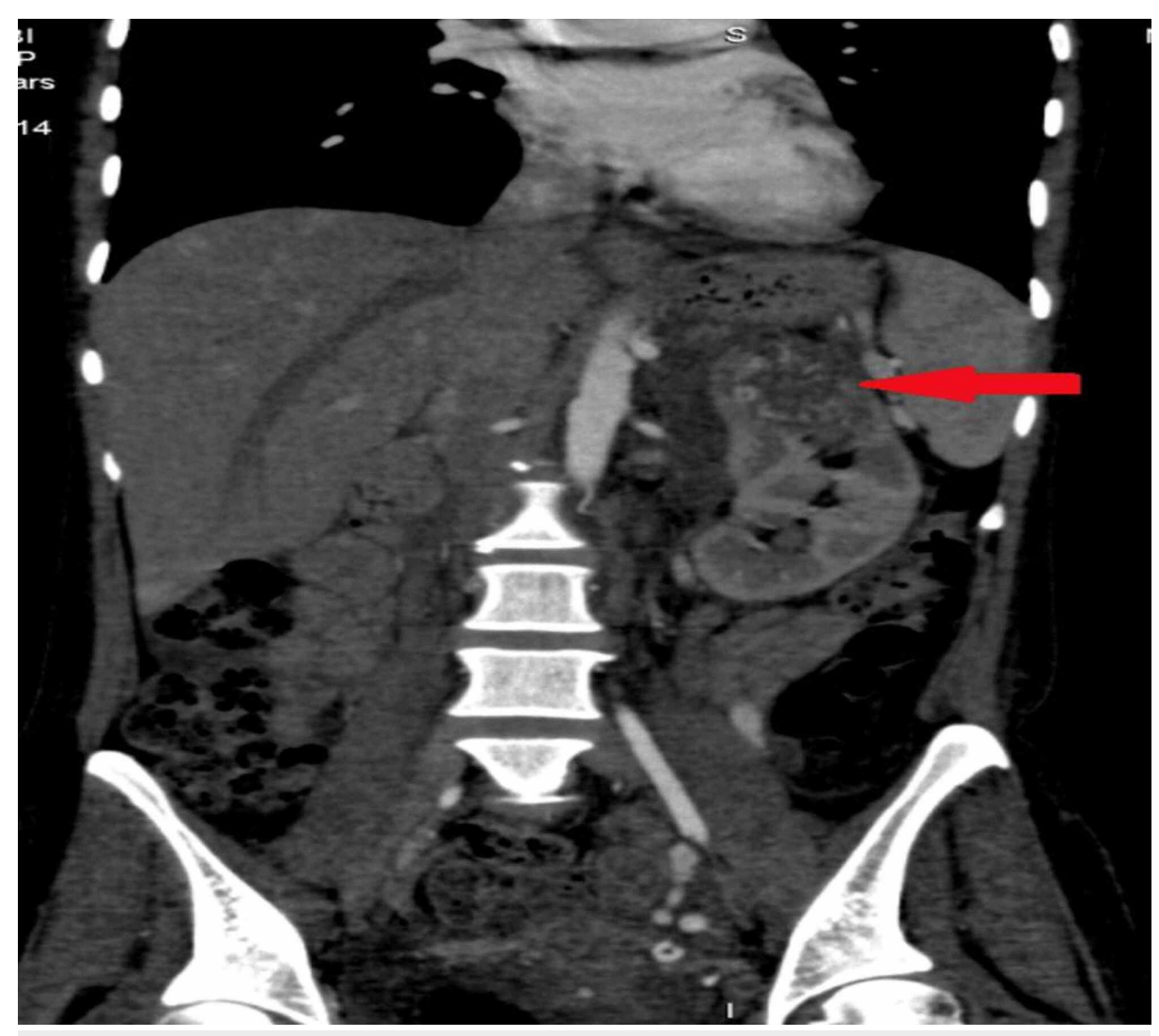

FIGURE 6: A similar enhancing soft tissue density lesion was seen on the upper pole of the left kidney 


\section{Cureus}

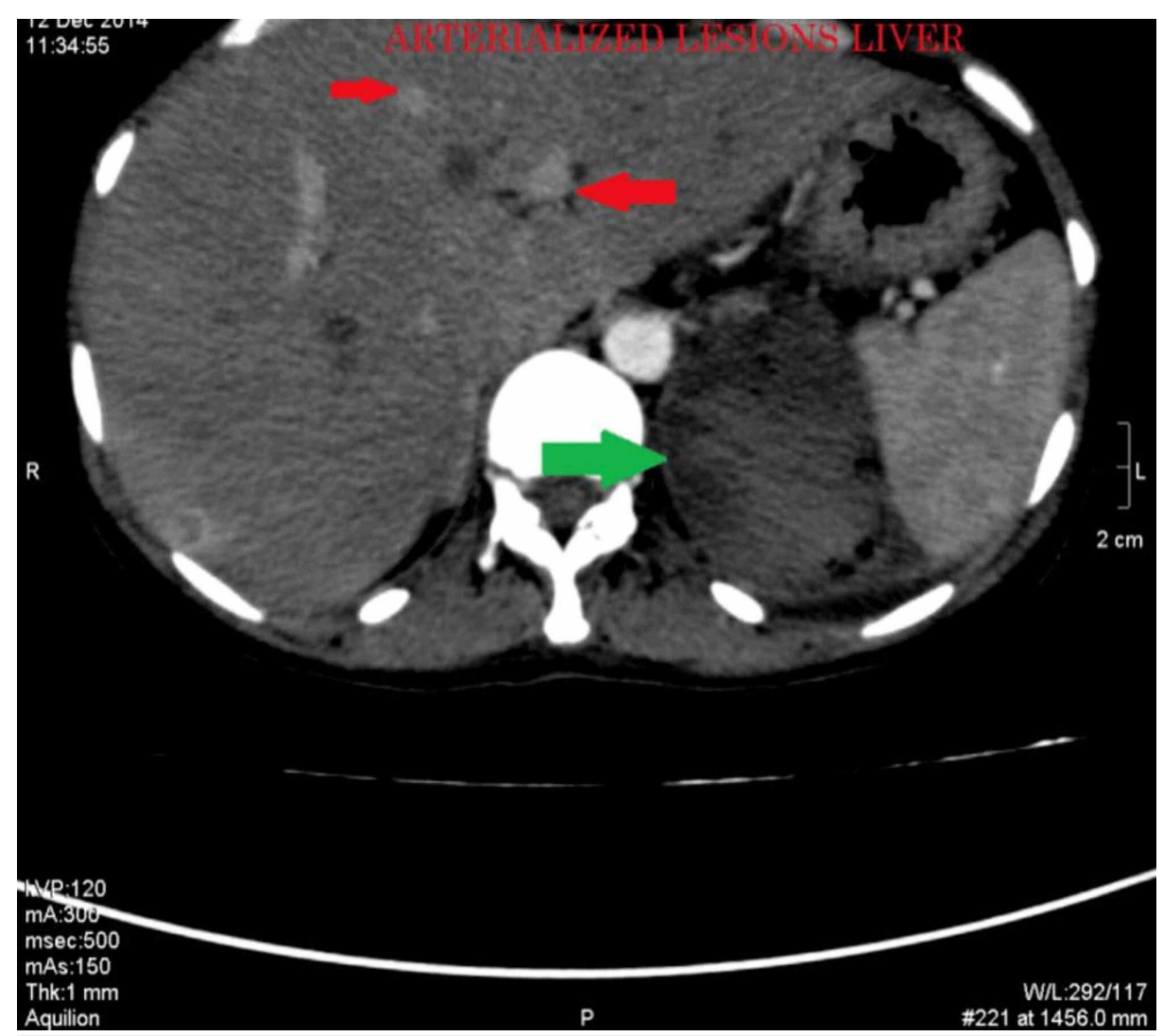

FIGURE 7: CECT abdomen axial section, arterial phase showing multiple arterialized lesions in the liver (red arrows) and a left subcapsular hematoma (green arrow)

CECT: contrast-enhanced computed tomography

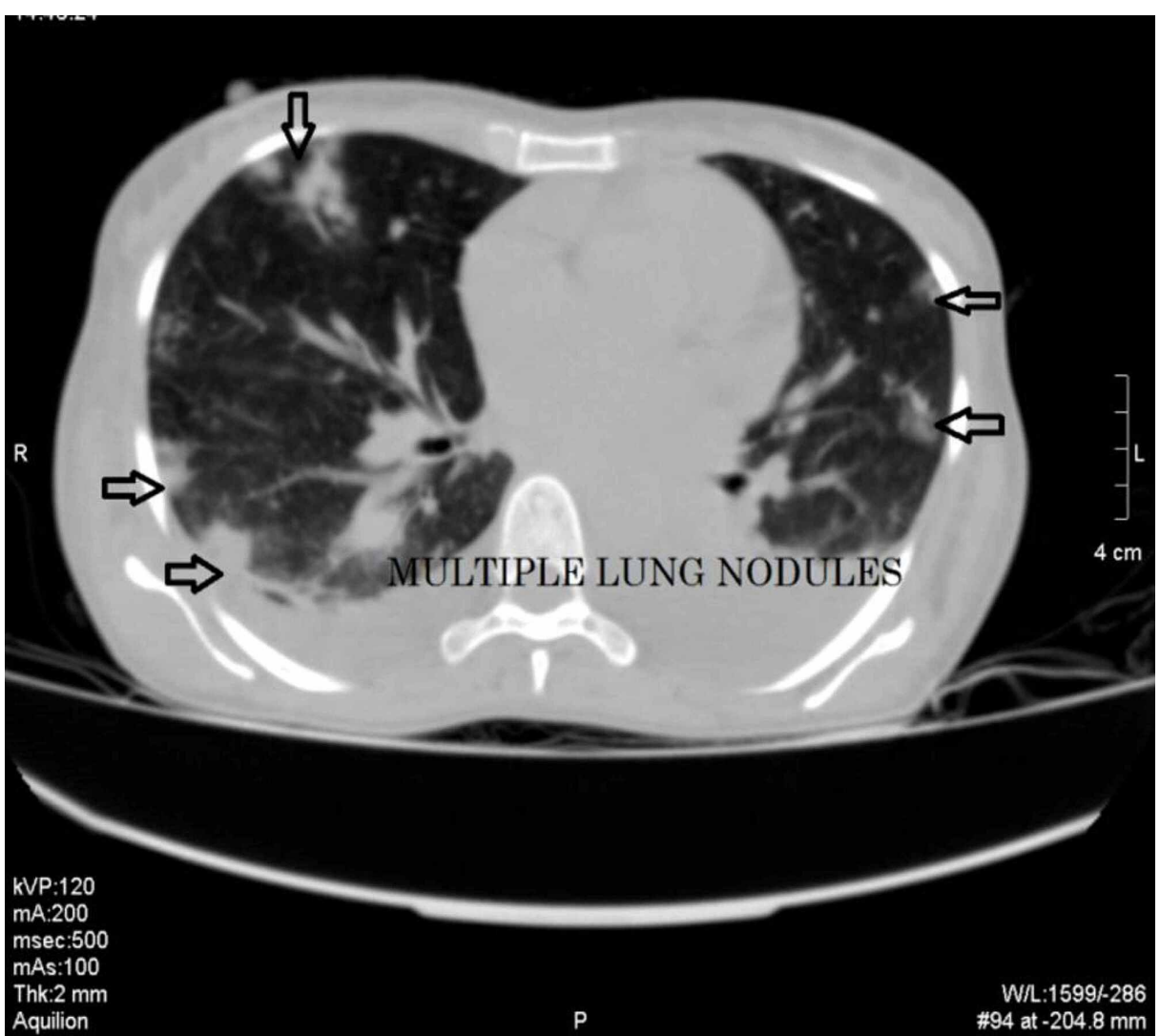




\section{Cureus}

FIGURE 8: CT chest lung window showing multiple pulmonary nodules and bilateral pleural effusion

CT: computed tomography

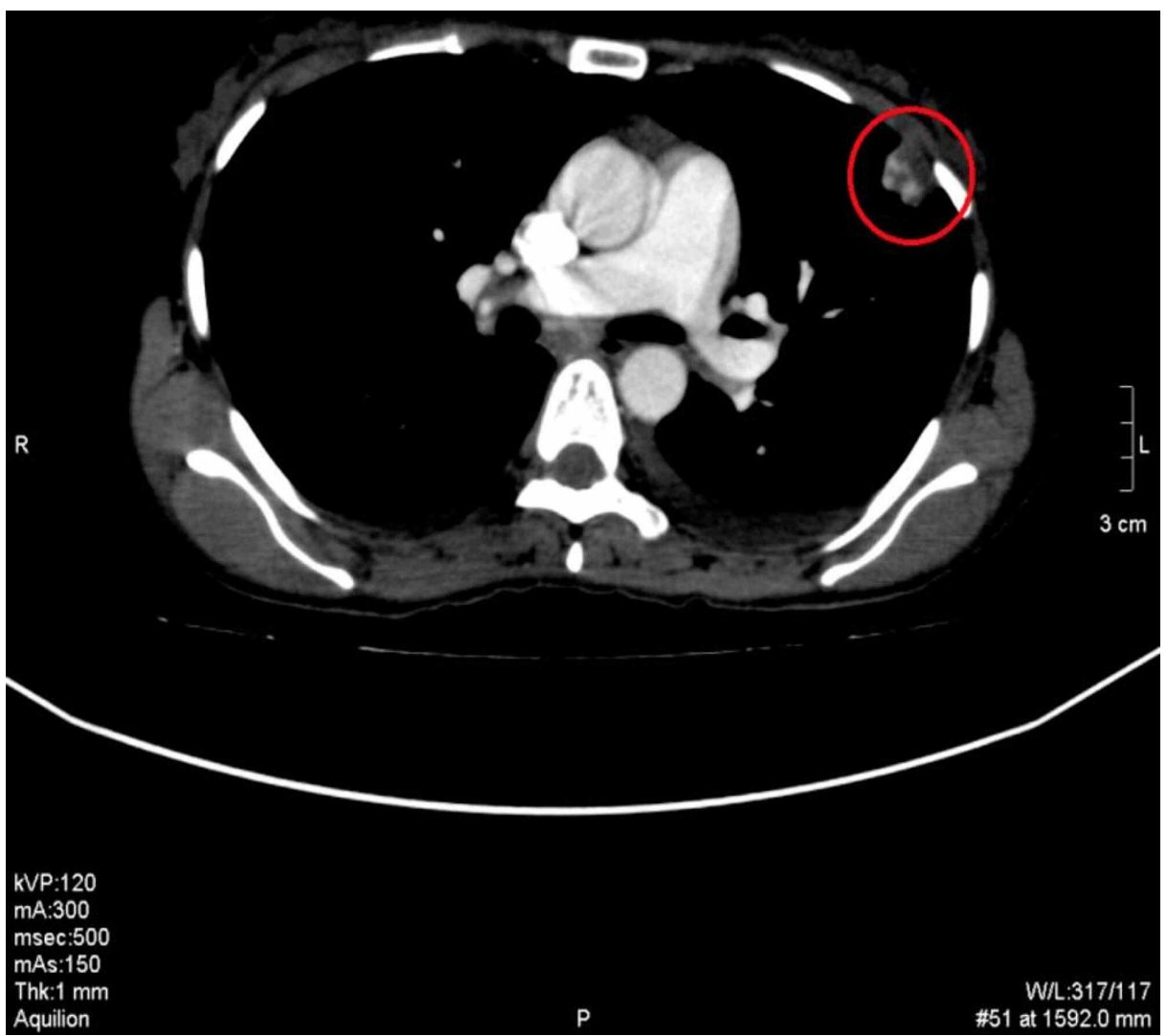

FIGURE 9: CECT chest, mediastinal window shows the vascular nature of the pulmonary nodule

CECT: contrast-enhanced computed tomography

CT angiogram showed the adnexal mass to be hypervascular, fed by branches of the left internal iliac artery, and drained by the left ovarian vein (Figure 10). 


\section{Cureus}

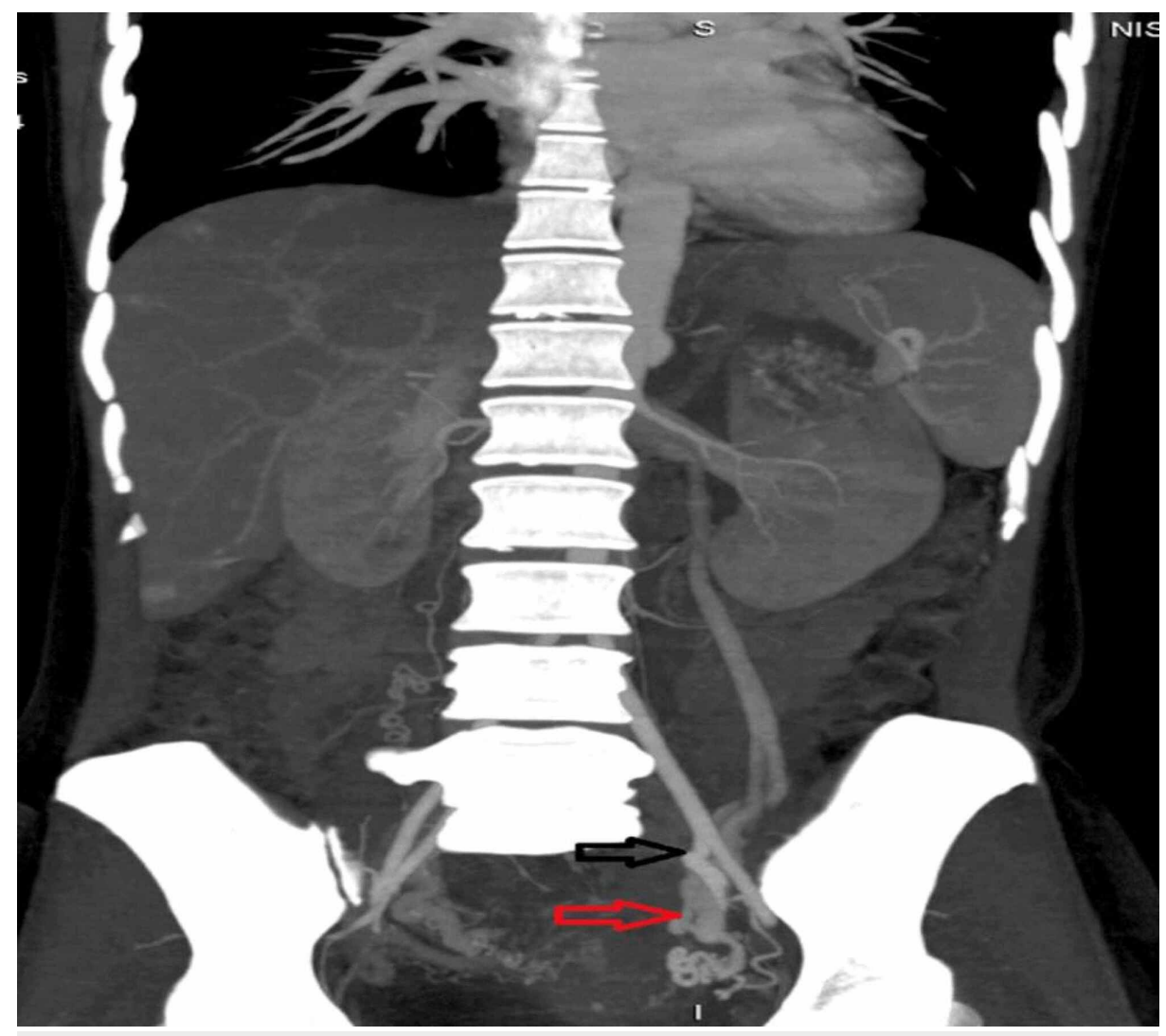

FIGURE 10: CT angiogram showing the mass to be hypervascular and fed by branches of the left internal iliac artery (black arrow) and drained by the left ovarian vein (red arrow)

CT: computed tomography

The kidneys' lesions were supplied by branches from the abdominal aorta, as shown by CT angiography (Figure 11). 


\section{Cureus}

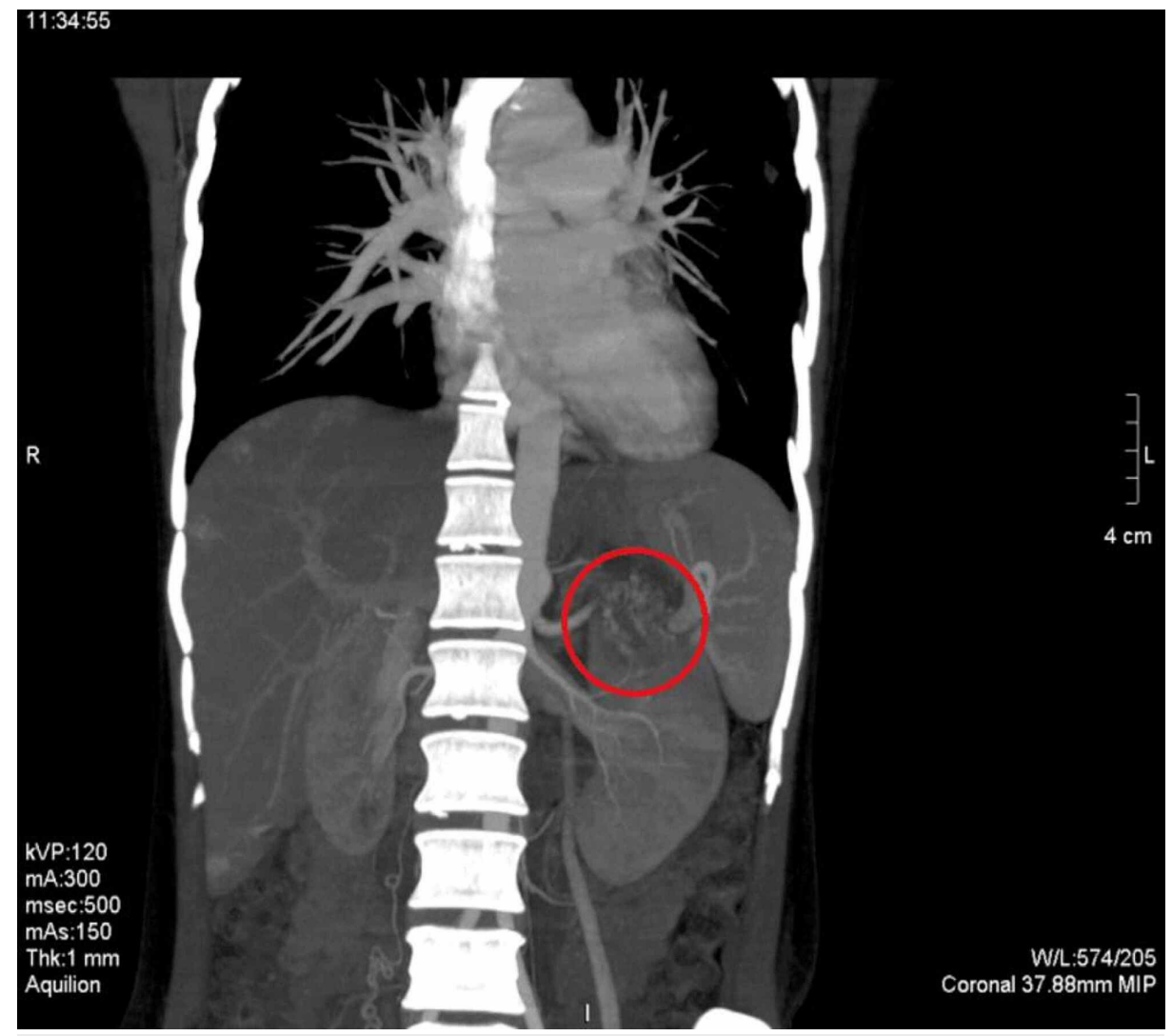

FIGURE 11: CT angiography shows the renal lesion to be hypervascular and fed by the branches from the aorta

CT: computed tomography

The surgeon released the tumor from its adhesions. She performed a left ovarian cystectomy, right salpingooophorectomy, and omentectomy. Histopathological examination revealed cellular neoplasm with tumor cells separated by hemorrhage zones and necrosis (Figure 12). A cut section of the ovary showed a graywhite tumor with areas of hemorrhage and necrosis.

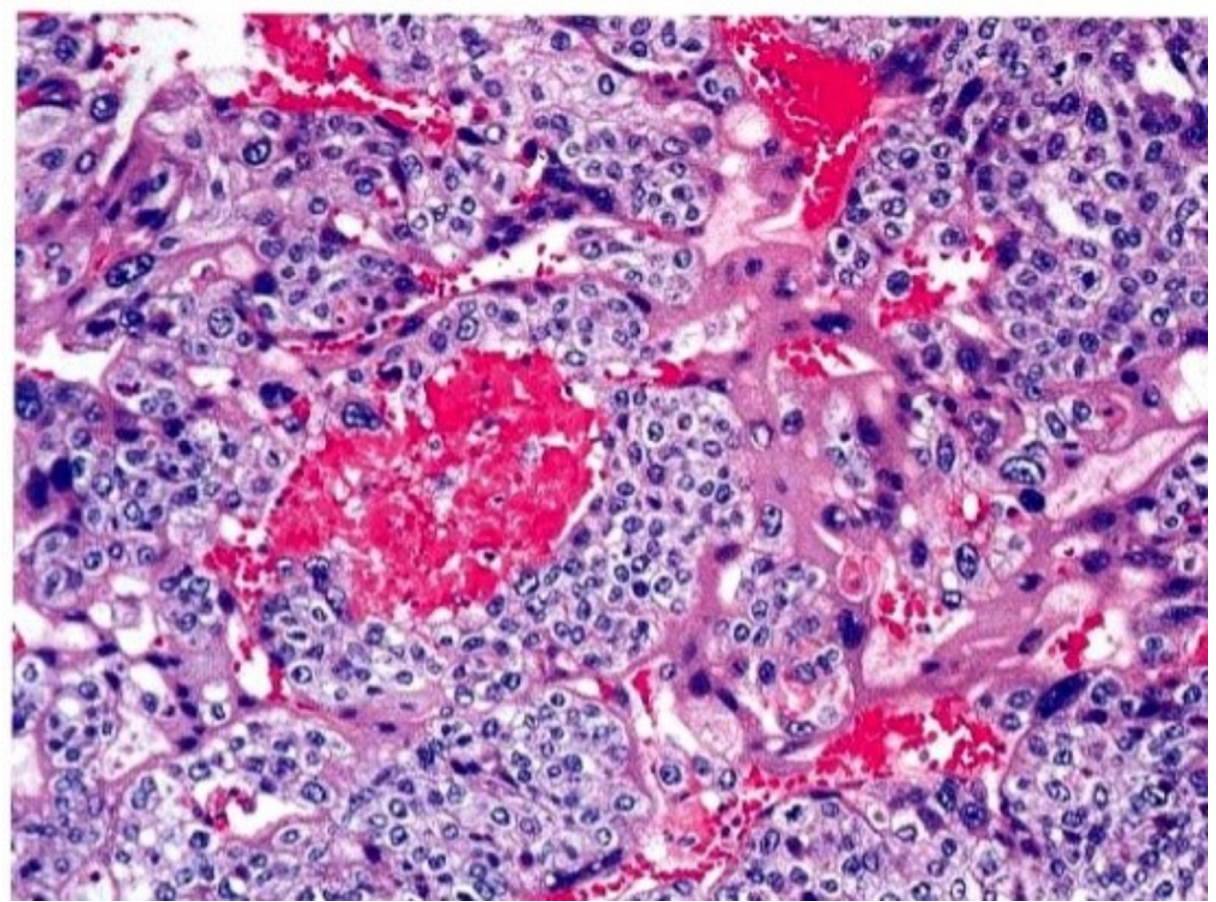


Her treatment regimen consisted of six cycles of chemotherapy with bleomycin, vincristine, and etoposide. She was on regular follow-up with human chorionic gonadotropin (HCG) levels, which came down to 1800 $\mathrm{IU} / \mathrm{ml}$ after three chemotherapy cycles. She was unable to complete the therapy and died due to cerebral metastasis.

\section{Discussion}

Choriocarcinoma is the most aggressive neoplasm of gestational trophoblastic diseases. It is because of its rapid growth and metastatic potential. There are two types of pure ovarian choriocarcinomas, gestational and non-gestational. The gestational type of ovarian choriocarcinoma can originate in any ectopic ovarian pregnancy or it can result as a metastasis from any distant site of choriocarcinoma. The non-gestational type is a rare germ cell tumor with trophoblastic differentiation [1]. The estimated incidence of gestational ovarian choriocarcinoma is one in 369 million pregnancies [5]. Non-gestational choriocarcinoma accounts for $0.6 \%$ or less of all ovarian neoplasms [6]. Intrauterine choriocarcinoma is the most common sub-type. Few cases involving some other anatomical sites such as the ovary, fallopian tube, and abdominopelvic cavity have also been reported [7-10].

The diagnosis of primary extra-uterine choriocarcinoma is challenging. There is no specific clinical manifestation attributable to ovarian choriocarcinoma. However, its presentation can mimic other pathologies like ovarian torsion and ectopic pregnancy [7-10]. Choriocarcinoma produces an enormous amount of beta-human chorionic gonadotropin ( $\beta$-HCG). The value ranges from three to 100 times more than a normal pregnancy. Serial measurements of the $\beta$-HCG level are of great diagnostic value. It also measures response to the treatment [11-12]. In a normal pregnancy, we can observe an intrauterine gestational sac on transvaginal sonography [12].

The potential sites where choriocarcinoma can metastasize involve uterine adnexa, pelvic cavity, lungs, brain, and liver. Rarely, it can also metastasize to the fetus via placental tissue [13]. The metastasis is commonly hemorrhagic because of trophoblastic cells' innate capacity to invade and erode vessel walls [14].

Chemotherapy is the management of choice for choriocarcinoma, even in metastatic disease. It has a curative rate of approximately $95 \%[11,13]$. Currently, four to six courses of cisplatin, etoposide, and bleomycin (PEB) regimen as conventional therapy are the therapeutic standard for disseminated ovarian germ cell tumor (GCT) with excellent activity and acceptable toxicity [15]. We recommend the early evaluation of all the female patients for ovarian carcinoma presenting with bleeding per vaginum. Early diagnosis can aid in better management of the patients as well as prevention from metastatic disease.

\section{Conclusions}

Non-gestational choriocarcinoma is a very rare ovarian neoplasm that is highly aggressive and usually present with vascular metastasis at the time of presentation. It poses diagnostic challenges because it mimics other more common conditions in women of childbearing age. Early diagnosis is crucial because the tumor is chemo-sensitive and has an excellent five-year survival rate despite early metastasis.

\section{Additional Information}

\section{Disclosures}

Human subjects: Consent was obtained or waived by all participants in this study. Conflicts of interest: In compliance with the ICMJE uniform disclosure form, all authors declare the following: Payment/services info: All authors have declared that no financial support was received from any organization for the submitted work. Financial relationships: All authors have declared that they have no financial relationships at present or within the previous three years with any organizations that might have an interest in the submitted work. Other relationships: All authors have declared that there are no other relationships or activities that could appear to have influenced the submitted work.

\section{References}

1. Mood NI, Samadi N, Rahimi-Moghaddam P, Sarmadi S, Eftekhar Z, Yarandi F: Pure ovarian choriocarcinoma: report of two cases. J Res Med Sci. 2009, 14:327-330.

2. Park SH, Park A, Kim JY, Kwon JH, Koh SB: A case of non-gestational choriocarcinoma arising in the ovary of a postmenopausal woman. J Gynecol Oncol. 2009, 20:192-194. 10.3802/jgo.2009.20.3.192

3. Goswami D, Sharma K, Zutshi V, Tempe A, Nigam S: Non-gestational pure ovarian choriocarcinoma with contralateral teratoma. Gynecol Oncol. 2000, 80:262-266. 10.1006/gyno.2000.6043 
4. Alifrangis C, Agarwal R, Short D, et al.: EMA/CO for high-risk gestational trophoblastic neoplasia: good outcomes with induction low-dose etoposide-cisplatin and genetic analysis. J Clin Oncol. 2013, 31:280-286. 10.1200/jco.2012.43.1817

5. Muto MG, Lage JM, Berkowitz RS, Goldstein DP, Bernstein MR: Gestational trophoblastic disease of the fallopian tube. J Reprod Med. 1991, 36:57-60.

6. Lv L, Yang K, Wu H, Lou J, Peng Z: Pure choriocarcinoma of the ovary: a case report . J Gynecol Oncol. 2011, 22:135-139. 10.3802/jgo.2011.22.2.135

7. Lurain JR, Sand PK, Brewer JI: Choriocarcinoma associated with ectopic pregnancy. Obstet Gynecol. 1986, 68:286-287.

8. Gerson RF, Lee EY, Gorman E: Primary extrauterine ovarian choriocarcinoma mistaken for ectopic pregnancy: sonographic imaging findings. AJR Am J Roentgenol. 2007, 189:280-283. 10.2214/ajr.05.0814

9. Chen MJ, Yang JH, Lin MC, Ho HN, Yang YS: An unusual gestational choriocarcinoma occurring primarily on the surface of a subserous leiomyoma. BJOG. 2004, 111:188-190. 10.1046/j.1471-0528.2003.00048.x

10. Maestá I, Michelin OC, Traiman P, Hokama P, Rudge MVC: Primary non-gestational choriocarcinoma of the uterine cervix: a case report. Gynecol Oncol. 2005, 98:146-150. 10.1016/j.ygyno.2005.03.045

11. Jacobs AJ, Newland JR, Green RK: Pure choriocarcinoma of the ovary. Obstetrical \& Gynecological Survey. 1982, 37:603-609. 10.1097/00006254-198210000-00001

12. Dehner LP: Gestational and non-gestational trophoblastic neoplasia: a historic and pathobiologic survey . Am J Surg Pathol. 1980, 4:43-58.

13. Speroff L, Fritz MA: Clinical Gynecologic Endocrinology and Infertility. Lippincott Williams \& Wilkins, Philadelphia; 2005.

14. Kidd D, Plant GT, Scaravilli F, McCartney ACE, Stanford M, Graham EM: Metastatic choriocarcinoma presenting as multiple intracerebral hemorrhages: the role of imaging in the elucidation of the pathology. J Neurol Neurosurg Psychiatry. 1998, 65:939-941. 10.1136/jnnp.65.6.939

15. Gershenson DM, Morris M, Cangir A, et al.: Treatment of malignant germ cell tumors of the ovary with bleomycin, etoposide, and cisplatin. J Clin Oncol. 1990, 8:715-720. 10.1200/JCO.1990.8.4.715 